\title{
Income Mobility and Financial Disadvantage: Australian Children
}

\section{Annie Abello and Ann Harding}

$\mathrm{T}$ This article provides the first Australian estimates of income mobility transitions among Australian children over a three year period. The results suggest that there is considerable income mobility but that, in the vast majority of cases, the shift is not dramatic. Transitions from the top to the bottom of the income spectrum, and vice versa, are very rare. Using a financial disadvantage line set at the cut-off point for the bottom quintile, the study also showed that about twelve per cent of all Australian children were in persistent financial disadvantage, experiencing financial disadvantage in all of the three years. An estimated 28 per cent of Australian children experienced financial disadvantage in at least one of the three years - about 40 per cent more than the proportion experiencing financial disadvantage in annual 'snapshots'. Comparison with overseas studies suggests that Australia does not appear to have greater mobility, perhaps contrary to the Australian perception of the 'fair go'. Analysis of the factors precipitating transitions into and out of financial disadvantage suggests that the emphasis by the Federal Government on requiring welfare recipients to work is an appropriate policy response, which may help to reduce the proportion of children who remain disadvantaged for extended periods of time.

The extent of income mobility and financial disadvantage among children is widely regarded as an important social issue. In Australia, the then Prime Minister, Bob Hawke, focussed attention on this issue in the 1980s, when promising that 'by 1990 no child shall live in poverty'. In Europe, the goal of promoting social inclusion has led to regular assessment of financial disadvantage and in such countries as the UK and Ireland there are strong anti-poverty initiatives in place (Department of Work and Pensions, 2002; Atkinson et al, 2001). A related key issue is whether or not there is considerable income mobility among children over time. As Bradbury, Jenkins and Micklewright observe, a child poverty rate of 10 per cent 'could mean that every tenth child is in poverty all the time or, at the other extreme, it could mean that all children are poor for one month in every ten' (2001:1). Knowing the extent to which the answer for a particular country tends towards the former situation rather than the latter is of crucial importance to policy makers, given the very different likely policy responses required.

One reason these issues attract so much concern is the growing body of evidence suggesting that adverse childhood experiences have a profound impact

Annie Abello is a Senior Research Fellow at NATSEM and Ann Harding is the inaugural director of NATSEM and Professor of Applied Economics and Social Policy at University of Canberra 
upon the rest of a child's life. Evidence shows that children who experience multiple forms of social and economic disadvantage are more likely to have poor health and well-being, with these adverse effects persisting throughout their lives and including lower subsequent rates of educational and labour market achievement and a greater likelihood of becoming teenage parents and serving prison sentences (Duncan et al, 1993, Poulton et al, 2002; UNICEF, 2000; Moore et al, 2002; Annie E Casey Foundation, 2003).

In Australia, there have been numerous studies of the extent of financial disadvantage among children at a particular point in time (Bradbury, 2003; Harding, Lloyd and Greenwell, 2001; Harding and Szukalska, 2000). But there has not been analysis of patterns of income mobility and financial disadvantage among Australian children over a longer time period. To undertake such analysis requires that we move beyond the weekly or yearly snapshot captured in the ubiquitous cross-section surveys of the population to longitudinal or panel data (where the same people and children are surveyed in each time period).

Until relatively recently, such longitudinal data have not been available for representative samples of the whole population. Full longitudinal data have previously been available for certain sub-groups of the population, including youth (through the Australian Youth Survey and its predecessor the Australian Longitudinal Survey - Bell, Rimmer and Rimmer, 1992), and recent immigrants (covered by the Longitudinal Study of Immigrants to Australia — see www.immi.gov.au/research/publications/index.htm for a list of most recent project reports). In addition, since our research was undertaken, the Australian Department of Family and Community Services has commissioned the Melbourne Institute to produce the HILDA longitudinal data (see www.melbourneinstitute.com for further information). Four waves of this survey are now available for analysis and the first papers on poverty dynamics using this data source are now emerging (Wooden and Headey, 2005; Marks, 2005). The Wooden and Headey study suggests that the majority of children who become poor do not remain poor for very long - and, while this is what we also find, this study is not directly comparable to ours because it uses a different definition of financial disadvantage (namely, half median equivalent disposable income).

This study examines income mobility and financial disadvantage among children using data from the Survey of Employment and Unemployment Patterns (SEUP), conducted by the Australian Bureau of Statistics (ABS, 2005). The SEUP was a longitudinal survey with information collected from the same individuals over three annual waves of interviews conducted in 1995, 1996 and 1997.

Internationally, the evidence suggests: that there is some income mobility among children, but that most children do not move all that far up or down the income spectrum; that the proportion of children who experience a spell of low income increases substantially as the time period extends beyond one year; and that most children do not remain persistently poor or financially disadvantaged for long periods of time (although sufficient variation between countries in the proportion of persistently poor children is revealed in these studies to underline 
the importance of looking at income dynamics) (Bradbury, Jenkins and Micklewright, 2001). For example, Gottschalk and Danziger (2001:142), who examine income mobility among children in the US over 10 years in the 1990s, echo the findings of other studies when they conclude that 'while there is some income mobility during childhood, children who started at the bottom of the distribution tended to remain there ... and children who started at the top of the distribution seldom fell very far'. Similarly, like other studies showing that the proportion of children facing a brush with low income is much higher than the proportion facing persistent poverty, Schulter (2001:166) found that 23 per cent of West German children experienced at least one year of low income during a five year period, but that only four per cent of West German children experienced low income in every year during the five years.

Do similar results emerge for Australia? Our study starts by looking at income dynamics, to establish the extent of overall income mobility among children within Australia. We then shift the focus to the lower end of the spectrum, to the persistence of financial disadvantage. Our financial disadvantage measures were chosen to be consistent as possible with results from Germany, Hungary, Ireland, Britain and the US (Bradbury, Jenkins and Micklewright, 2001).

Section 2 of this paper describes the SEUP data and key methodological features of our study, while Section 3 examines patterns of income mobility among Australian children. Section 4 analyses how persistent financial disadvantage is, and the characteristics of those in persistent financial disadvantage, while Section 5 concludes.

\section{Data and Methodology}

The SEUP sample comprises three subgroups, and our study utilises the population reference group (PRG) sample, which is a random sample of the population aged 15-59 years (with a sample size of 2311 people in the first wave, of which some 14 per cent was lost between wave 1 and wave 3). The sample used for our study was considerably smaller than this for three reasons. First, a substantial proportion of respondents to the SEUP survey did not provide estimates of their incomes and, following concerns about the way in which incomes had been imputed by the ABS for this group, we dropped them from our study (see Abello and Harding, 2004 for full details of this and other aspects of the methodology). The SEUP includes both 'current weekly income' (income in the week immediately preceding the survey) and annual income from the previous financial year. We focused on annual rather than current income, as the former is generally regarded as a more reliable measure of economic well-being. Second, more than half of those captured in the SEUP sample did not have children and so were deleted from our analysis. Third, the SEUP collected income data only for the respondent to the survey and their spouse (if any). As a result, in cases where the respondent was a dependent student, information about the income of their parents was not collected. If we left these dependent students in the sample then we would have had extraordinarily high rates of financial disadvantage. 
Accordingly, we deleted those records where the respondent was a dependent student (approximately five per cent of records in wave 1). After these three amendments, we were left with a sample of 607 records in wave 1, 593 in wave 2, and 667 in wave 3 for all dependent children, or with 542, 512 and 574 respectively for children aged under 15 years only.

The SEUP dataset comes with a set of weights that indicates the number of persons in the whole population represented by each observation in the sample survey — that is, the weights are applied to the data to make the survey results more representative of the whole population and are also the means by which researchers 'gross up' the sample results to estimates for all of Australia. The ABS has calculated longitudinal weights for the SEUP data that take into account the representativeness of each respondent as well as the issue of sample attrition. We used three sets of weights, depending on the nature of the analysis. For analysis of data on a per wave basis, the ABS weights associated with each wave were used for each wave's data. For analysis of transitions through all three waves a common set of weights across the waves was required, so the wave 3 longitudinal weights calculated by the ABS were used. As the ABS only calculated the weight of the responding person to the SEUP survey, we had to assume that the weight of the income unit (and thus of any children) was the same as the weight of the responding person. All of our results are for persons, rather than for families.

We used a family's annual cash income before income tax as the basic indicator of their standard of living - that is, gross or total income in the preceding financial year. Most studies of financial disadvantage use disposable (after income tax) income as the measure of resources. However, the SEUP did not collect data on post-tax income and it was not possible for us to accurately impute income tax onto the survey. Income is defined as 'regular cash receipts' and includes wages and salaries, business and investment income, and government cash transfers such as pensions and family allowance. There were some extreme values in the SEUP data which would have unduly influenced the results (particularly means), so any negative value was set to zero and any weekly income greater than $\$ 5000$ was set to $\$ 5000$ (see Greenwell, Lloyd and Harding (2001:1617), for options regarding treatment of negative incomes).

A couple with three children and a gross income of $\$ 25,000$ will not be as affluent as a couple with one child and a gross income of $\$ 25,000$ - because, in the former case, the income is supporting five people while, in the latter case, it is only supporting three people. Researchers typically use equivalence scales to adjust income, so as to take account of such differences in family size and composition. There is no agreement, either in Australia or internationally, about which is the 'right' equivalence scale to use (ABS, 2004:52). We have used the original OECD equivalence scale which assumes, for example, that couples with two children require 59 per cent more income than couples without children to reach the same standard of living. The OECD equivalence scale carries a weight of one for the first adult in the unit, 0.7 for any other adult and 0.5 for each child. 
The 'income unit' is the group among whom income is assumed to be shared equally. Our study employs the ABS definition of the income unit, which means that an income unit is defined as either a couple with dependent children, a couple without dependent children, a sole parent with dependent children, or a single person. A dependent child is defined as a child aged less than 15 years or a 15-24 year old in full-time study and still living in the parental home. Following convention, throughout the paper we have referred to the income unit as 'the family'.

Finally, we use two financial disadvantage thresholds. These were set at the boundaries for the lowest quintile and lowest decile of equivalent family gross income of all Australian children in each wave. That is, there are 20 per cent of the weighted sample of children in each quintile in each wave, and 10 per cent in each decile.

\section{Income Mobility}

This section begins with a description of the extent and pattern of income dynamics among children. Every child in the sample was classified into a family income decile group in each of the three years (that is, 10 per cent of all children were in each decile), and the resulting group classification in one year was crosstabulated with the group classification at another year to reveal the pattern of change in income groups over the period. The one-year transition or movement is based on the pattern of movement for two one-yearly intervals, that is, movements starting in year 1 and ending in year 2, and movements starting in year 2 and ending in year 3. The two-year movements are those between years 1 and 3 .

Over one year, 36 per cent of all children remained in the same decile group they started out in, whether it was the first, second or tenth decile (Table 1). Over two years the percentage declined to 34 per cent. Thus, about two-thirds of all children switched income deciles over the course of just one year, suggesting considerable mobility. If only children under 15 years of age are considered, the percentages are 37 and 29 per cent respectively.

Table 1 also shows the proportion of children in the sample who were in the same or neighbouring (one higher or one lower) income group. It shows that most movements in one or two years are over a short range. For example, although only 36 per cent of the sample stayed in the same decile group over a one-year interval, more than double this proportion (76 per cent) remained in the same decile or moved to a neighbouring decile group. Similarly, while 61 per cent of all children remained in the same quintile group after one year, 92 per cent were in the same or an adjacent quintile group. 
Table 1: Overall Mobility Between Income Groups: One- and Twoyear Intervals, 1994-95 to 1996-97

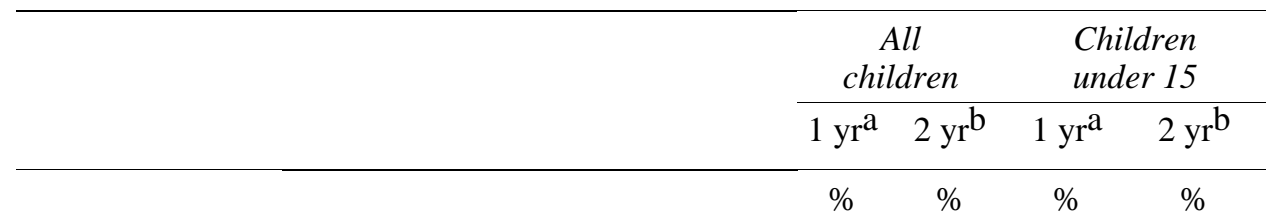

Proportion remaining in the same:

Decile group

$\begin{array}{llll}36 & 34 & 37 & 29\end{array}$

Quintile group

$\begin{array}{llll}61 & 58 & 61 & 50\end{array}$

Proportion remaining in the same or adjacent:

$\begin{array}{llllll}\text { Decile group } & 76 & 70 & 75 & 71\end{array}$

$\begin{array}{lllll}\text { Quintile group } & 92 & 89 & 93 & 88\end{array}$

Notes: $\mathrm{a}=$ Average of transitions between waves 1 and 2 and waves 2 and 3 .

$\mathrm{b}=$ Transition between waves 1 and 3 .

\section{Low Income and High Income Persistence}

The data showing the degree of mobility between income groups can also be used to show persistence in low income and high income groups over the short term (Table 2).

The degree of short-term low-income persistence depends on the low-income threshold chosen. For example, if the cut-off is the lowest decile, then about onequarter of children who were in the bottom decile in either years 1 or 2 were still there one year later (and thus about three-quarters moved out of extreme financial disadvantage). If the threshold is raised to the lowest quintile, the profile is very different, with almost three-quarters remaining in the same bottom quintile group and only about one-quarter escaping to higher income quintiles.

The degree of short-term high-income persistence also depends on the definition of the income threshold. If we focus on the top income decile, then less than seven out of every 10 children in the top decile in one year have moved out of that decile by the following year. This is a much lower degree of mobility than is apparent for children in the lowest income decile. However, once the income measure is extended to the top quintile, there is relatively little difference in mobility between the top quintile and the bottom quintile. As Table 2 shows, in each case 72 per cent of children who were in either the top or bottom quintile in one year remained in that quintile in the following year. 
Table 2: Low Income and High Income Persistence: One-year Interval $^{\text {a }}$, 1994-95 to 1996-97

\begin{tabular}{lcc}
\hline & $\begin{array}{c}\text { All } \\
\text { children }\end{array}$ & $\begin{array}{c}\text { Children } \\
\text { under 15 }\end{array}$ \\
\hline $\begin{array}{l}\text { Proportion in the same low income group } \\
\text { one year later }\end{array}$ & $\%$ & $\%$ \\
$\begin{array}{l}\text { Lowest decile group } \\
\text { Lowest quintile group }\end{array}$ & 26 & 28 \\
$\begin{array}{l}\text { Proportion in the same high income group } \\
\text { one year later }\end{array}$ & 72 & 72 \\
$\begin{array}{l}\text { Richest decile group } \\
\text { Richest quintile group }\end{array}$ & 67 & 64 \\
\hline
\end{tabular}

Notes: $\mathrm{a}=$ Average of transitions between waves 1 and 2 and waves 2 and 3 .

The figures in the third row of the table can be used to show that if $20 \%$ of children were in the lowest quintile group in one year, then $72 \%$ of these were still there in the following year (that is, $14.4 \%$ of the total sample - or [20 $+20 * 0.72]$ ). Conversely, $28 \%$ were not still there the following year, so that $25.6 \%$ of the sample experienced one bout of low income in any two year period (that is, $[20+20 * 0.28]$ ).

This again suggests that there is much greater apparent mobility when looking at income deciles — but that most mobility only involves a move from one decile to an adjacent decile. Figure 1 shows the proportion of children remaining in the same decile over a one-year interval averaged over the period 1994-95 to 1996-97. For the majority of children - those in income deciles one to seven - between about 20 and 40 per cent remain in the same decile from one year to the next. For those in the top two income deciles, the picture is very different, with about half to three-quarters remaining in the same decile from one year to the following year.

Overall, 36 per cent of children remained in the same annual income decile over the period. Of the 64 per cent who did change deciles, most moved to an adjacent decile as shown by the top line in Figure 1. The proportion of children remaining in the same income decile or moving to an adjacent decile was around 80 per cent for the lower deciles, 75 per cent for the middle deciles, and 80 per cent for the top deciles. The foregoing confirms that there is more short-range stability at the top of the income distribution than at the bottom - but that right across the income spectrum, about four out of every five children remain in the same or an adjacent income decile from one year to the next. 
Figure 1: Degree of Movement Between Income Deciles: One-year Interval (Average over the period 1994-95 to 1996-97 ${ }^{\text {a }}$ )

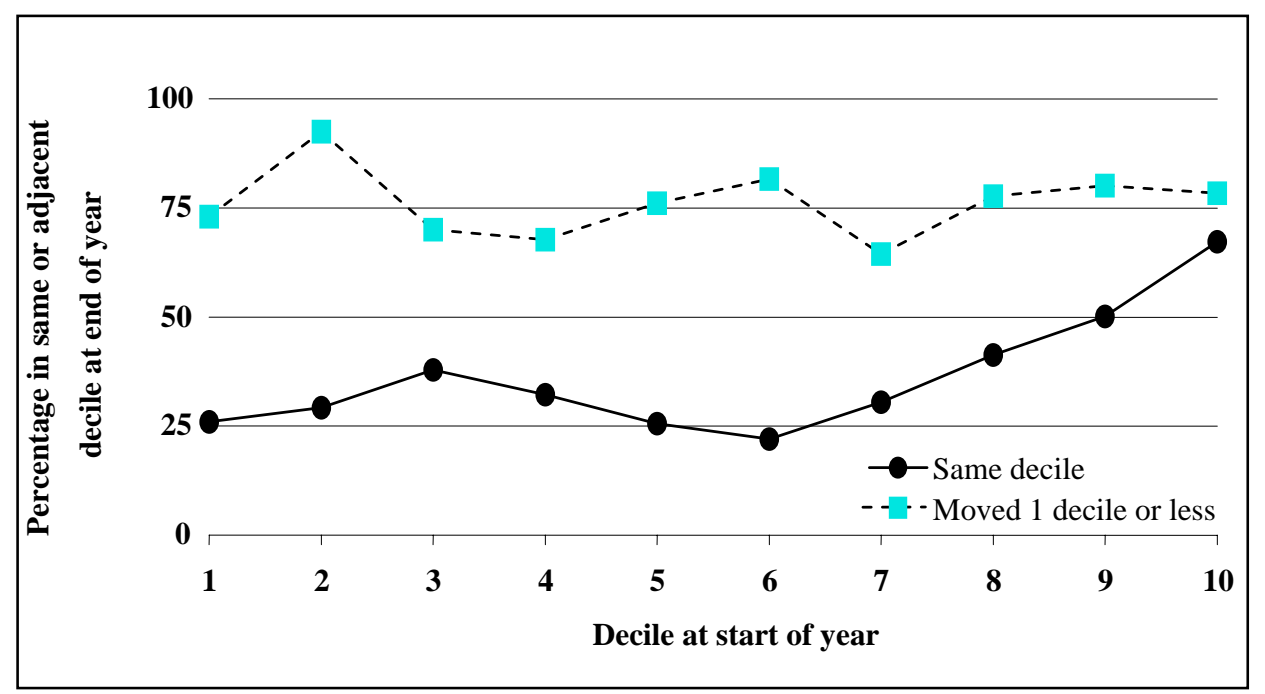

Note: $\mathrm{a}=$ Average of transitions between waves 1 and 2 and waves 2 and 3.

\section{Long-range Mobility}

The above suggests that about one-fifth of children live in families whose circumstances change sufficiently to shift them two or more deciles across the income distribution. Are there many children shifting from the very bottom to the very top of the income spectrum - or from the very top to the very bottom? Table 3 summarises long-range mobility, defined here as the proportion of the richest group that move to the poorest group in the next period, and vice versa. The numbers indicate that very little long-range movement occurs, with only one in every hundred children in the highest income decile in one year falling to the lowest income decile in the following year. In our sample, no children were in families that catapulted from the lowest income decile in one year to the highest income decile in the following year. Even if the period of observation is extended from one year to two, the proportions are still quite small. This confirms that most of the children moving out of the poorest income groups or the richest groups do not move very far. While it must be emphasised that we are only looking here at a three-year period, these results nonetheless echo those for other countries, suggesting that for the majority of children their place in the income ladder is relatively fixed. 
Table 3: Long-range Mobility: One- and Two- year Intervals, 1994-95 to 1996-97

\begin{tabular}{lcccc}
\hline & \multicolumn{2}{c}{ All children } & \multicolumn{2}{c}{ Children under 15 } \\
\cline { 2 - 5 } & $1 \mathrm{yr}^{\boldsymbol{a}}$ & $2 \mathrm{yr}^{\boldsymbol{b}}$ & $1 \mathrm{yr} \boldsymbol{\boldsymbol { a }}$ & $2 \mathrm{yr}^{\boldsymbol{b}}$ \\
\hline $\begin{array}{l}\text { Proportion of richest income group } \\
\text { moving to poorest income group }\end{array}$ & $\%$ & $\%$ & $\%$ & $\%$ \\
$\begin{array}{l}\text { Top decile to bottom } \\
\text { Top quintile to bottom }\end{array}$ & 1 & 0 & 0 & 0 \\
$\begin{array}{l}\text { Proportion of poorest income group } \\
\text { moving to richest income group }\end{array}$ & 2 & 3 & 2 & 3 \\
$\begin{array}{l}\text { Bottom decile to top } \\
\text { Bottom quintile to top }\end{array}$ & & & & \\
\hline
\end{tabular}

Notes: $\mathrm{a}=$ Average of transitions between waves 1 and 2 and waves 2 and 3 .

$\mathrm{b}=$ Transition between waves 1 and 3 .

Finally, Table 4 shows the full mobility matrix by income decile for children from one year to the next, key features of which were summarised in Tables 1 to 3. It sheds further light on the extent of mobility through the income spectrum. For example, it shows that 73 per cent of all children in the bottom income decile in one year remained in either the bottom or second income decile one year later - and that none moved up to the top decile. But Table 4 also shows us that about one-fifth of all those children in the bottom income decile in one year had moved up to deciles three and four a year later, suggesting a substantial improvement in their economic well-being. Conversely, however, of all those children who were in decile 3 in one year and thus above our financial disadvantage thresholds, about one in every eight lived in families that had slipped down to the bottom income decile one year later. 
Table 4: Movement Between Annual Income Deciles: One-year Transitions, All Children, 1994-95 to 1996-97a

\begin{tabular}{|c|c|c|c|c|c|c|c|c|c|c|c|c|}
\hline \multirow{2}{*}{$\begin{array}{l}\text { Decile in } \\
\text { first period }\end{array}$} & \multirow{2}{*}{$\begin{array}{l}\% \text { of all } \\
\text { children }\end{array}$} & \multicolumn{10}{|c|}{ Decile in subsequent period } & \multirow[t]{2}{*}{ Total } \\
\hline & & 1 & 2 & 3 & 4 & 5 & 6 & 7 & 8 & 9 & 10 & \\
\hline & $\%$ & $\%$ & $\%$ & $\%$ & $\%$ & $\%$ & $\%$ & $\%$ & $\%$ & $\%$ & $\%$ & $\%$ \\
\hline 1 & 10 & 26 & 47 & 15 & 4 & 1 & 3 & 1 & 1 & 2 & 0 & 100 \\
\hline 2 & 10 & 42 & 29 & 21 & 2 & 2 & 2 & 0 & 2 & 0 & 0 & 100 \\
\hline 3 & 10 & 12 & 13 & 38 & 19 & 11 & 1 & 0 & 1 & 0 & 4 & 100 \\
\hline 4 & 10 & 1 & 7 & 25 & 32 & 11 & 13 & 6 & 1 & 0 & 3 & 100 \\
\hline 5 & 10 & 1 & 2 & 6 & 20 & 26 & 30 & 7 & 6 & 2 & 0 & 100 \\
\hline 6 & 10 & 3 & 0 & 5 & 2 & 25 & 22 & 34 & 4 & 3 & 2 & 100 \\
\hline 7 & 10 & 4 & 1 & 3 & 1 & 8 & 20 & 30 & 14 & 11 & 8 & 100 \\
\hline 8 & 10 & 1 & 0 & 4 & 7 & 2 & 5 & 20 & 41 & 17 & 3 & 100 \\
\hline 9 & 10 & 2 & 0 & 0 & 0 & 4 & 3 & 11 & 16 & 50 & 14 & 100 \\
\hline 10 & 10 & 1 & 1 & 0 & 1 & 2 & 1 & 6 & 11 & 11 & 67 & 100 \\
\hline
\end{tabular}

Note: $\mathrm{a}=$ Average of transitions between waves 1 and 2 and waves 2 and 3 .

\section{Financial Disadvantage}

We have used two measures of financial disadvantage based on the thresholds set previously: those children whose equivalent gross family income places them in the lowest quintile of children are defined to be in financial disadvantage, while those whose equivalent gross family income places them in the lowest decile are defined to be in severe financial disadvantage.

\section{Persistent Financial Disadvantage}

This section describes the extent of persistent financial disadvantage among children. It should be noted, however, that our definition of persistent financial disadvantage is constrained by the availability of data for only a three year period as we have no information on equivalent income before and after this period; other studies, such as Duncan, Coe and Hill (1984) define the persistently poor over a much longer time period (eight or more years out of ten). Further, this analysis requires that the respondents have provided data on their income for all three years, so sample sizes are even smaller.

We start here by identifying children who were in financial disadvantage in 1994-95 and then look at what happened to them over the following two years. Using the lowest income decile as our severe financial disadvantage cut-off, only 
one in every 100 children were in persistent severe financial disadvantage over the three years - that is, they were in families with incomes below this financial disadvantage threshold in all three years (Table 5). About five in every 100 children were in severe financial disadvantage in 1994-95 and still in severe financial disadvantage in 1995-96.

Table 5: Proportion of Children in Financial Disadvantage by Number of Years, 1994-95 to 1996-97

\begin{tabular}{lcccc}
\hline & \multicolumn{4}{c}{ Financial disadvantage threshold } \\
\cline { 2 - 5 } & \multicolumn{2}{c}{ All dependent children } & Children aged under 15 \\
\cline { 2 - 5 } & $\begin{array}{c}\text { Lowest } \\
\text { decile }\end{array}$ & $\begin{array}{c}\text { Lowest } \\
\text { quintile }\end{array}$ & $\begin{array}{c}\text { Lowest } \\
\text { decile }\end{array}$ & $\begin{array}{c}\text { Lowest } \\
\text { quintile }\end{array}$ \\
\hline $\begin{array}{l}\text { Proportion in financial } \\
\text { disadvantage in: }\end{array}$ & $\%$ & $\%$ & $\%$ & $\%$ \\
All 3 years & 1 & 12 & 1 & 14 \\
2 years only & 5 & 3 & 5 & 4 \\
1 year only & 13 & 13 & 15 & 13 \\
$\begin{array}{l}\text { Proportion in financial } \\
\text { disadvantage in: }\end{array}$ & & & & \\
All 3 years & 1 & 12 & 1 & 14 \\
At least 2 years & 6 & 15 & 6 & 18 \\
At least 1 year & 19 & 28 & 21 & 31 \\
\hline
\end{tabular}

If the threshold is raised to the lowest quintile income cut-off, the proportion persistently in financial disadvantage in all three years rises to twelve in every 100 children. About 13 in every 100 children experienced two years of financial disadvantage (Table 5). With respect to children under the age of 15 years, we find slightly higher proportions in persistent financial disadvantage (and correspondingly, slightly smaller proportions never in financial disadvantage).

While only a small proportion of children were in financial disadvantage in every year, many experienced financial disadvantage at some point during the three years. Starting with the figures based on the lowest decile cut-off, 1 per cent were in severe financial disadvantage in all three years, 5 per cent experienced severe financial disadvantage in any two years, and 13 per cent had a brush with severe financial disadvantage in only one year. These proportions imply that, during the three years, 1 per cent of the sample had three spells of severe financial disadvantage, 6 per cent had at least two spells of severe financial disadvantage, and 19 per cent had at least one spell of severe financial disadvantage (lower panel of table 5). In other words, the lives of one-fifth of all children in the sample had been touched by severe financial disadvantage over the three years. 
If the financial disadvantage threshold is raised to the lowest quintile of current income, the proportion having at least one spell of financial disadvantage rises to nearly a third of the sample (28 per cent) - 40 per cent more than the proportion for a single year. Conversely, this means that over two-thirds of all children in our sample never experienced financial disadvantage within the three years, using the lowest quintile measure.

The relatively high proportion of children in the sample experiencing some financial disadvantage over the period 1995-97 is another manifestation of the earlier finding about mobility between income groups being common at all points along the income range.

The extent of persistent financial disadvantage can also be gauged from another perspective - the proportion of children in financial disadvantage at a point in time compared with the proportions in financial disadvantage throughout the entire period. Of the group of children defined to be in financial disadvantage based on the lowest decile cut-off in 1994-95, table 6 shows that 23 per cent were still in severe financial disadvantage one year later and 12 per cent were in severe financial disadvantage in all three years. When the cut-off is the lowest quintile of current income, the percentages are much higher. Of the children in financial disadvantage in 1994-95, 71 per cent were still in financial disadvantage a year later and two-thirds were in financial disadvantage in all three years.

Table 6: Children in Financial Disadvantage in 1994-95 and Still in Financial Disadvantage in 1995-96 and in or 1996-97

\begin{tabular}{|c|c|c|c|c|}
\hline & \multicolumn{4}{|c|}{ Financial disadvantage threshold } \\
\hline & \multicolumn{2}{|c|}{ All dependent children } & \multicolumn{2}{|c|}{ Children aged under 15} \\
\hline & $\begin{array}{l}\text { Lowest } \\
\text { decile }\end{array}$ & $\begin{array}{l}\text { Lowest } \\
\text { quintile }\end{array}$ & $\begin{array}{c}\text { Lowest } \\
\text { decile }\end{array}$ & $\begin{array}{l}\text { Lowest } \\
\text { quintile }\end{array}$ \\
\hline & $\%$ & $\%$ & $\%$ & $\%$ \\
\hline $\begin{array}{l}\text { Proportion in financial disadvantage } \\
\text { in year } 1\end{array}$ & 100 & 100 & 100 & 100 \\
\hline $\begin{array}{l}\text { Proportion still in financial } \\
\text { disadvantage in year } 2\end{array}$ & 23 & 71 & 24 & 72 \\
\hline $\begin{array}{l}\text { Proportion still in financial } \\
\text { disadvantage in years } 2 \text { and } 3\end{array}$ & 12 & 67 & 13 & 68 \\
\hline
\end{tabular}

Despite the sensitivity of the results to the financial disadvantage threshold used, the foregoing numbers show that a large proportion of those in financial disadvantage in the first year remained in financial disadvantage through all three years of the SEUP survey. These results also indicate that there is a greater likelihood of staying in financial disadvantage among those who have been in financial disadvantage at some point in time than among the population as a 
whole. Jarvis and Jenkins (1996:16) indicate that the reason for this is straightforward - 'those in the low income stock have disproportionately long low income spell durations compared to the population as a whole; those with relatively high exit rates and hence, shorter durations, leave first, leaving behind the longer duration people'.

\section{Characteristics of the Persistently Financially Disadvantaged}

Do children in persistently financially disadvantaged families have some particular set of characteristics, or are they are just a random subset of those who are financially disadvantaged at a particular point in time? To address this issue, we briefly look at selected characteristics of children financially disadvantaged in all three waves, and compare the distribution by family type and economic activity for this group, with the corresponding distribution of children financially disadvantaged in wave 1 , and all children in wave 1 . In this section we focus the analysis on financial disadvantage defined using the lowest quintile of current income. The primary reason for choosing current income over annual income is that the variables important to our analyses (on family type and economic activity) are contemporaneously associated with current income.

Of the total sample of children in persistently financially disadvantaged families, 42 per cent were in sole parent families. The corresponding proportion for children who were financially disadvantaged in wave 1 was close to half that (22 per cent), while of the total sample of children in wave 1 only 12 per cent were in sole parent families.

Another major difference between the persistently financially disadvantaged and those financially disadvantaged in wave 1 is that the former are overrepresented in families where one or both parents are not working. Forty one per cent of persistently financially disadvantaged children were in couple families where one or both parents were unemployed or not in the labour force, compared with 32 per cent for those financially disadvantaged in wave 1, and 8 per cent for the whole sample of children. In addition, 39 per cent of persistently financially disadvantaged children were in sole parent families where the parent was not in the labour force in wave 1, compared with 18 per cent for all those financially disadvantaged in wave 1 , and 6 per cent for the whole sample.

\section{Conclusion}

The regular national income surveys conducted by the Australian Bureau of Statistics mean that we are accustomed to receiving up-to-date information about the extent of financial disadvantage and income inequality at a particular point in time. But for many policy makers and researchers, the degree of movement into and out of financial disadvantage and the accompanying mobility in income distribution are equally important social indicators. As Bradbury, Jenkins and Micklewright (2001:130) note, even when conventional cross-sectional child poverty rates are not increasing, there may still be a decline in mobility - 
resulting in undetected increases in the proportion of children experiencing long spells of poverty. 'In other words, changes in dynamic patterns can have as important an impact upon child well-being as changes in the cross-sectional poverty rate'.

Looking at income mobility first, while there was extensive movement between family income groups from one year to the next, the moves were generally not large. Some 64 per cent of children moved from one decile group to another between one year and the next. This suggests a reasonably comparable degree of income mobility in Australia to that found by Bradbury, Jenkins and Micklewright for Britain (59 per cent), the USA and West Germany (57 per cent), and Ireland (60 per cent) (2001:103). Our analysis showed that children who were rich in one year were unlikely to slip into financial disadvantage the next year, and children who were poor in one year were unlikely to be rich the next year. This lack of long-range movement across the income spectrum is also consistent with the findings for other countries (for example, Jervis and Jenkins, 1996:40; Gottschalk and Danziger, 2001).

The proportion of Australian children experiencing at least one brush with financial disadvantage during the three years was higher than the proportion in financial disadvantage in any particular year. Over three years, the proportion of children facing at least one bout of financial disadvantage was 28 per cent about 40 per cent higher than the proportion estimated to be in financial disadvantage during any single year (using the bottom quintile cut-off as the definition of financial disadvantage). The proportion of children facing at least one year of financial disadvantage out of any two years in our sample can be calculated from Table 2 and stands at 25.6 per cent. This again appears to be highly comparable with those in other industrialised countries, with Bradbury, Jenkins and Micklewright reporting that the proportion of children who were ever in the bottom quintile over a two year period was 26.4 per cent for Germany and the USA, 25.3 per cent for Ireland and 27.1 per cent for Britain (2001:107).

While the SEUP data reveals relatively low estimates of persistent financial disadvantage across the three years, a look at the proportion staying in financial disadvantage after each wave shows that the majority of children in financial disadvantage in the first wave remained there in successive waves. Taken in conjunction with the information on high exit rates from poverty, the SEUP data shows that in Australia, while a significant proportion of children slip into and out of financial disadvantage, a small pool of children tend to remain in financial disadvantage, at least for the three years that we have data.

We can again use the figures in table 2 to calculate that 14.4 per cent of children stayed in the bottom quintile for any two consecutive years: this compares with 13.9 per cent for Britain and 14.2 per cent for the USA (Bradbury, Jenkins and Micklewright, 2001:107), providing support for the view that low income persistence in Australia does not appear to be lower than in other industrialised countries and perhaps contrary to the traditional view of Australia as the land of the 'fair go'. Unfortunately, we do not have internationally comparable data for a three year span. 
An important issue for policy makers is determining the causes of persistent financial disadvantage, and transitions into and out of financial disadvantage. As one might expect, children in persistent financial disadvantage were overrepresented in couple families where one or both parents were not working and in sole parent families (particularly where the parent was not in the labour force). There was also a strong association between changes in a child's family characteristics and changes in income or financial disadvantage status. Changes in the number of earners in the family had a clear-cut association with transitions out of or into financial disadvantage, while decreases in the number of children (via children reaching adulthood and leaving the parental home) were more important for transitions out of financial disadvantage (Abello and Harding, 2004:29). These findings are consistent with studies of income dynamics overseas, which suggest that households with two earners are less likely to be financially disadvantaged and more likely to subsequently rise again above the low income threshold if they do slip below it (OECD, 1998:184), while households headed by a sole parent are more likely to remain persistently poor (Jervis and Jenkins, 1996; Huff-Stevens, 1995; Oxley, Dang and Antolin, 2000; OECD, 1998; Desrosiers et al, 2002).

Our results, like those of the other income dynamics studies indicated above, thus suggest that government policies that focus on reducing unemployment and encouraging labour force participation - including employment and training programs and longer term measures to increase worker skills - should have a positive effect upon child financial disadvantage. The international evidence suggests that it is important to identify those who are persistently poor, with this group requiring greater policy attention than those who are poor for only a short period - and also that it is appropriate to complement income measures with other measures of deprivation to help policy makers identify and target this group (Nolan, Maitre and Watson, 2001).

In recent years, the policy landscape has changed greatly in Australia: the creation of new longitudinal datasets has challenged the perception of mobility among the sole parent population, with studies suggesting that the average period of receipt of income support may be as long as 12 years (Gregory and Klug, 2003).

In the 2005 Budget and subsequently, the Australian government announced a range of welfare to work measures, including requiring sole parents whose youngest child is aged over 7 years to seek at least 15 hours of paid work a week (Andrews, 2005). While this measure should help to ensure that Australian children do not remain financially disadvantaged over long periods of time, such sole parents are also to be placed on a form of income support which has a lower payment rate and a much harsher income test than the current pension (and thus higher effective marginal tax rates on earned income - Harding et al, 2005). As a result, the final impact upon child financial disadvantage will depend upon how these opposing factors play out in practice.

Given the importance of multiple income earners in the prevention of child financial disadvantage, the high effective tax rates faced by secondary income earners in Australia are also an important related issue. It is often the case that the 
very people who stand to benefit from greater participation in the workforce are the ones that face the greatest financial disincentives to do so (Toohey and Beer, 2004). Child care subsidies can also play an important role in helping to boost the labour force participation of secondary earners and sole parents, so the persistence of child care affordability and availability problems is another area of potential policy attention (McNamara, Cassells and Lloyd, 2005).

\section{References}

Abello, A. and A. Harding (2004), 'The dynamics of child poverty in Australia', Discussion Paper No 60, National Centre for Social and Economic Modelling, University of Canberra

Australian Bureau of Statistics (2005), Technical Paper Australian's Employment and Unemployment Patterns Expanded CURF: 1994 to 1997, Catalogue no. 6286.0.55.002, Canberra.

Australian Bureau of Statistics (2004), Household Income and Income Distribution, 200203, Catalogue No 6523.0, Canberra

Andrews, K. (2005), 'Welfare to Work - Increasing participation of parents', Budget 2005-06, Office of the Hon Kevin Andrews MP, Parliament House, Canberra.

Annie E. Casey Foundation, (2003), Kids Count Online, www.aecf.org/kidscount, as cited in Daly, A. and D. Smith (2003), 'Reproducing Exclusion or Inclusion? Implications for the Wellbeing of Indigenous Australian Children', Technical Report Discussion Paper No.253, CAEPR, The Australian National University, Canberra.

Atkinson, T., B. Cantillon, E. Marlier and B. Nolan (2001), Indicators for Social Inclusion in the European Union, Oxford University Press, Oxford.

Bell, D., R. Rimmer and S. Rimmer (1992), 'Poverty in Australia: A Study of the Implications of Education, Household Formation and the Labour Market Experience of the Young', pp.319-351 in R. Gregory and T. Karmel (eds), Youth in the Eighties: Papers from the Australian Longitudinal Survey Research Project, Centre for Economic Policy Research, The Australian National University, Canberra.

Bradbury, B. (2003), 'Child Poverty: A Review', Policy Research Paper No 20, Commonwealth Department of Family and Community Services, Canberra.

Bradbury, S. Jenkins and J. Micklewright (2001), 'The Dynamics of Child Poverty in Seven Industrialised Nations’, pp.92-132 in B. Bradbury, S. Jenkins and J. Micklewright (eds), The Dynamics of Child Poverty in Industrialised Countries, Cambridge University Press, Cambridge.

Department of Work and Pensions (2002), 'DWP Commissioned Research on Social Security’, http://www.dwp.gov.uk/asd/asd5/Biblio.pdf.

Desrosiers, H., L. Gingras and G. Neill (2002), 'Children's Economic and Family Circumstances: A World in Motion', Paper presented to the $17^{\text {th }}$ meeting of the International Society for the Study of Behavioural Development, Ottawa. 
Duncan, G., B. Gustafsson, R. Hauser, G. Schmauss, H. Messinger, R. Muffels, B. Nolan and J. Ray (1993), 'Poverty Dynamics in Eight Countries', Journal of Population Economics 6(3):215-34.

Duncan, G., R. Coe and M. Hill (1984), 'The Dynamics of Poverty', pp. 33-70 in G. Duncan, R. Coe, M. Corcoran, M. Hill, S. Hoffman, and J. Morgan (eds), Years of Poverty, Years of Plenty, Institute for Social Research, Ann Arbor, Michigan.

Gottschalk, P and S. Danziger (2001), 'Income Mobility and Exits from Poverty of American Children', pp. 135-153 in B. Bradbury, S. Jenkins and J. Micklewright (eds), The Dynamics of Child Poverty in Industrialised Countries, Cambridge University Press, Cambridge.

Greenwell, H, R. Lloyd and A. Harding (2001), 'An Introduction to Poverty Measurement Issues’, Discussion Paper No 55, National Centre for Social and Economic Modelling, University of Canberra

Gregory, R. and E. Klug (2003), 'A Picture Book Primer: Welfare Dependency and the Dynamics of Female Lone Parent Spells', Australian National University, http://econrsss.anu.edu.au/Staff/gregory/pdf/PictureBookPrimer_17_01_03_Facs.pdf.

Harding, A., Q. Vu, R. Percival and G. Beer (2005), 'Welfare-to-Work Reforms: Impact on Sole Parents', Agenda 12(3):195-210.

Harding, A., R. Lloyd and H. Greenwell (2001), Financial Disadvantage in Australia 1900 to 2000: The persistence of poverty in a decade of growth, The Smith Family, Camperdown, NSW, November.

Harding, A., and A. Szukalska (2000), 'The Changing Face of Child Poverty in Australia, 1982 to 1997-98', Paper presented to the 7th Australian Institute of Family Studies Conference, Sydney, 26 July.

Huff-Stevens, A. (1995), 'Climbing Out of Poverty, Falling Back In: Measuring the Persistence of Poverty over Multiple Spells', WP No 5390, National Bureau of Economic Research, Cambridge Ma.

Jarvis, S. and S. Jenkins (1996), 'Changing Places: Income Mobility and Poverty Dynamics in Britain', Working Paper no. 96-19, ESRC Research Centre on Micro-Social Change, University of Essex, Colchester.

McNamara, J., R. Cassells and R. Lloyd (2005), 'Persistence of Problems with Child Care Affordability and Availability: Evidence from the HILDA Survey', Paper presented to the $9^{\text {th }}$ Australian Institute of Family Studies Conference, (available from www.natsem.canberra.edu.au).

Moore, K., D. Glei, A. Driscoll, M. Zaslow and Z. Redd (2002), 'Poverty and Welfare Patterns: Implications for Children', Journal of Social Policy 31(2):207-27, as cited in Daly, A. and D. Smith (2003), 'Reproducing Exclusion or Inclusion? Implications for the Wellbeing of Indigenous Australian Children', Technical Report Discussion Paper No.253, CAEPR, The Australian National University, Canberra.

Marks, G. (2005), 'Dynamics of Financial Disadvantage’, Agenda 12(4):309-322. 
Nolan, B., B. Maitre and D. Watson (2001), 'Child Income Poverty and Deprivation Dynamics in Ireland', pp 196-214 in Bradbury, S. Jenkins and J. Micklewright (eds), The Dynamics of Child Poverty in Industrialised Countries, Cambridge University Press, Cambridge.

OECD (1998), 'Low Income Dynamics in Four OECD Countries', OECD Economic Outlook, No 64, December.

Oxley, H, T. Dang and P. Antolin (2000), 'Poverty Dynamics in Six OECD Countries', OECD Economic Studies 30:7-52.

Poulton, R., A. Caspi, B. Milne, W. Thompson, A. Taylor, M. Sears and T. Moffitt (2002), 'Association Between Children's Experience of Socioeconomic Disadvantage and Adult Health: A Life-Course Study', The Lancet 360(November 23):1640-1645.

Schulter, C. (2001), 'Child Poverty in Germany: Trends and Persistence’, pp. 154-173 in Bradbury, S. Jenkins and J. Micklewright (eds), The Dynamics of Child Poverty in Industrialised Countries, Cambridge University Press, Cambridge.

Toohey, M. and G. Beer (2004), 'Financial Incentives to Work for Married Mothers Under A New Tax System’, Australian Journal of Labour Economics 7(1):53-69.

Wooden, M. and B. Headey (2005), 'Poverty in Australia: Insights from HILDA', Melbourne Institute News Issue 7(March):2-3.

UNICEF (2000), A League Table of Child Poverty in Rich Nations, UNICEF, Florence.

The authors wish to thank Bruce Bradbury and Anthony King for their extremely helpful comments on earlier drafts of this paper. Many thanks also to our anonymous referees for their comments. 